\title{
What would ecological climate change law look like? Developing a method for analysing the international climate change regime from an ecological perspective
}

\author{
Olivia Woolley
}

\section{Correspondence}

Email: olivia.woolley@abdn.ac.uk

Statements and commitments made in the climate change treaties record the desire of their parties to preserve ecosystem functionality and situations that depend on this as an outcome of their collective response to global warming. Despite this, little attention has been given in climate law literature to the appropriateness of the legal framework they establish for achieving their stated ecological goals. This may be due in part to the lack of a method for analysing the climate change treaties from an ecological perspective. This article seeks to develop such a method by considering the key questions that States would need to answer when formulating a treaty for combating global warming in ways that advance goals associated with maintaining current structures and functions of ecosystems. It also identifies ways in which detailing of the Paris Agreement's provisions could be used to promote ecosystem preservation as an outcome of international climate action.

\section{INTRODUCTION}

Statements made in documents preceding the adoption of the 1992 United Nations Framework Convention on Climate Change (UNFCCC) ${ }^{1}$ and in the UNFCCC and the 2015 Paris Agreement ${ }^{2}$ recognize that the stabilization of atmospheric greenhouse gases is not an end in and of itself. Rather, it is pursued with a view to preventing outcomes such as the deterioration of the Earth's ecosystems and therefore of their capacity to support life, including by affording services on which humans and all other species depend. United Nations General Assembly Resolution 44/228, which initiated efforts leading to the UNFCCC's negotiation, prioritizes action against threats to ecosystems posed by trends such as global warming that 'if allowed to continue, could disrupt the global ecological balance, jeopardize the life-sustaining qualities of the Earth and lead to an ecological catastrophe', and recognizes that 'decisive, urgent and global action is vital to protecting the ecological balance of the Earth' ${ }^{3}$ The UNFCCC notes in its preamble that 'additional warming of the Earth's surface and atmosphere' due to increasing atmospheric concentrations of greenhouse gases 'may adversely affect natural

\footnotetext{
${ }^{1}$ United Nations Framework Convention on Climate Change (adopted 29 May 1992, entered into force 21 March 1994) 1771 UNTS 107 (UNFCCC). The UNFCCC is a treaty that creates a legal framework for action by States to address anthropogenic greenhouse gas growth and combat climate change. It has been ratified by 197 parties, including all 193 member States of the United Nations, and is therefore of significant importance for determining how climate change is addressed. Detailed accounts of the treaty can be found in D Bodansky, J Brunnée and L Rajamani, International Climate Change Law (Oxford University Press 2017) 118-159; and P Sands et al, Principles of International Environmental Law (4th edn, Cambridge University Press 2018) 299-307.

2 Paris Agreement (adopted 12 December 2015, entered into force 4 November 2016) 55 ILM 743 (2016). The Paris Agreement is the second instrument adopted by States under the UNFCCC to further develop and detail their responsibilities and rights when tackling climate change. Out of 197 parties to the Convention, 185 had ratified the Paris Agreement by the end of June 2019. The near-unanimity of ratification and the rate of uptake indicate that the Paris Agreement has a high degree of international support, although the United States gave notice of its intention to withdraw at the earliest possible date in law (4 November 2020) in 2017. Detailed accounts of the treaty can be found in Bodansky et al (n 1) 209-257; and Sands et al (n 1) 318-330.

${ }^{3}$ UNGA, 'United Nations Conference on Environment and Development' UN Doc A/RES/44/228 (22 December 1989).
} 
ecosystems and humankind'. ${ }^{4}$ It describes the '[a]dverse effects of climate change', a term defined in the treaty as meaning 'changes in the physical environment or biota resulting from climate change which have significant deleterious effects on the composition, resilience or productivity of natural and managed ecosystems', as 'a common concern of humankind' and calls on its parties to combat them. ${ }^{5}$ The Paris Agreement notes the importance 'of ensuring the integrity of all ecosystems, including oceans, and the protection of biodiversity' ${ }^{6}$ It also recognizes 'the fundamental priority of safeguarding food security and ending hunger', neither of which can be observed without maintaining services such as food provisioning and soil formation that ecosystems perform. ${ }^{7}$ The UNFCCC further obliges parties to "promote and cooperate in the conservation and enhancement, as appropriate, of sinks and reservoirs of all greenhouse gases not controlled by the Montreal Protocol, including biomass, forests and oceans as well as other terrestrial, coastal and marine ecosystems' ${ }^{8}$

In addition, ecosystem preservation and enhancement are linked explicitly or by implication with the objectives of the UNFCCC and Paris Agreement. Stabilization of greenhouse gas emissions under the UNFCCC should be achieved within a time frame 'sufficient to allow ecosystems to adapt naturally to climate change' and 'to ensure that food production is not threatened'. ${ }^{9}$ Uncertainty over how the ultimate objective should be interpreted and concerning its legal status prevents it from providing clear guidance to parties on how to address global warming, ${ }^{10}$ but its wording suggests that the UNFCCC's drafters had in mind the avoidance of significant change in ecosystem structure and functioning due to excessive climatic disturbance as an outcome of international climate action. The Paris Agreement's goals of '[i]ncreasing the ability to adapt to the adverse impacts of climate change and foster climate resilience' and of 'enhancing adaptive capacity, strengthening resilience and reducing vulnerability to climate change' may be ill-defined, but provide a basis for questioning the adequacy of parties' nationally determined contributions which are not aimed at forestalling climate-driven ecological deterioration. ${ }^{11}$ Ecosystem preservation and enhancement are also relevant to limiting growth in global average temperatures and reaching net zero greenhouse gas emissions by the second half of the 21 st century to the extent that the continued functioning of ecosystems performing sink and reservoir functions assists with keeping emissions and removals of greenhouse gases in balance. ${ }^{12}$

These preambular statements and provisions beg a question which, despite its relevance for achieving the goals they espouse, has not been given close scrutiny in academic literature on climate law to date: to what extent have the UNFCCC and the two treaties made under it, the 1997 Kyoto Protocol ${ }^{13}$ and the Paris Agreement, established an appropriate legal framework for preserving the functioning of ecosystems and the life supporting services they

\footnotetext{
${ }^{4} \mathrm{UNFCCC}$ (n 1) preamble.

5 ibid preamble, arts 1(1) and 3(1).

${ }^{6}$ Paris Agreement (n 2) preamble.

7 ibid.

${ }^{8}$ UNFCCC (n 1) art 4(1)(d); Paris Agreement (n 2) art 5(1) advises that parties 'should' take such action.

${ }^{9} \mathrm{UNFCCC}$ (n 1) art 2.

${ }^{10}$ D Bodansky, 'The United Nations Framework Convention on Climate Change: A Commentary' (1993) 18 Yale Journal of International Law 451, 499-500; Bodansky et al (n 1) 125-126.

${ }^{11}$ Paris Agreement (n 2) arts 2(1)(b) and 7(1).

12 ibid arts 2(1)(a) and 4(1).

${ }^{13}$ Kyoto Protocol to the United Nations Framework Convention on Climate Change (adopted 10 December 1997, entered into force 16 February 2005) 2303 UNTS 162. The Protocol, the first treaty adopted under the UNFCCC, had 192 parties as at the end of June 2019. It is not examined further in this article as it does not contain statements or provisions requiring ecosystem preservation as an outcome of climate action. Its focus is on adding detail to developed country obligations for greenhouse gas emission reduction under the UNFCCC by setting specific targets for decarbonization. Detailed accounts of the treaty can be found in Bodansky et al (n 1) 160-208; and Sands et al (n 1) 307-317.
} 
afford in the face of global warming specifically? This raises a second question which must be answered before the first question is considered: on what basis can the framework's ecological appropriateness be assessed?

Making such an assessment involves more than considering how climate change affects ecosystems (although this is an essential starting point). This knowledge is not determinative of the appropriate response by States to climate change as a threat to ecosystem functionality. For example, it tells States that ecosystems are highly complex and that much about them and how human activities affect them is not understood, but it does not tell them how to respond to this lack of knowledge and understanding including by developing appropriate controls to promote the realisation of desired outcomes. Instead, States must make political decisions based on scientific knowledge available to them, including of what is not known, and guided by applicable legal principles and relevant theories (e.g. those referred to in the article on the appropriate response to circumstances posing risks of catastrophic outcomes even when the likelihood of their occurrence is thought to be low). ${ }^{14}$

In view of this, developing a basis for assessing the ecological appropriateness of the legal framework created by the UNFCCC and Paris Agreement for combating climate change requires thought about the questions that States would need to consider when formulating a treaty which seeks to promote ecosystem preservation as an outcome of international climate action and about conclusions which awareness of ecological effects and prevailing conditions should lead them to draw. This approach allows the formulation of a hypothetical instrument which can then be used as a comparator with the actual treaties.

The main aim of this article is therefore to develop a basis for highlighting the strengths and weaknesses of the legal framework created by the climate change treaties for ecosystem preservation. This enables identification not only of the current regime's deficiencies, but also of opportunities for its enhancement without having to formulate a new treaty, an important consideration in view of the several years of problematic negotiations preceding the Paris Agreement. ${ }^{15}$ In addition, it offers guidance on change needed to the regime and parties' contributions under it to enhance the prospects that ecosystems confronted by changing planetary conditions will be able to maintain existing structures, functions and services. A key conclusion is that the principal obligation for parties under a treaty which seeks to preserve and bolster the capacity of ecosystems to support life despite global warming should be to strengthen their resilience to disturbance by restoring them and reducing pressures placed on them by all human activities. Reducing greenhouse gas growth would remain the priority focus in view of the major ecological threat climate change poses by eroding resilience whilst simultaneously threatening ecosystems' ability to retain current structures and functions. However, the means and rate by which greenhouse gas reduction should be conducted would be informed by the overarching ecological goal.

The starting point is to record the likely impacts on ecosystems of global warming, which parties would need to have in mind when developing a treaty intended to address them (Section 2.1). The article then goes on to answer the key questions that States would need to consider when deciding on the collective response required to the current situation. First, is precise knowledge available of how and when climate change will affect ecosystems (Section 2.2)? In short, it is not. Layers of uncertainty about how and when climate change will combine with other sources of disturbance from human activities to affect ecosystems preclude regulation based on the reliable prediction of outcomes. Second, how can States decide on when and with what rapidity to address the causes of climate change-driven ecological

\footnotetext{
${ }^{14}$ See Section 2.3.

${ }^{15}$ L Rajamani, 'Differentiation in the Emerging Climate Change Regime' (2013) 14 Theoretical Inquiries in Law 151.
} 
deterioration despite this lack of knowledge (Section 2.3)? I argue that a precautionary analysis would assist them with recognizing an appropriate response. This would make apparent the need for the reduction of pressures responsible for the erosion of ecosystem resilience, the property which enables them to maintain current structures and functions in the face of disturbance, and for action to bolster resilience as a bulwark against the consequences of climatic alteration to be pursued as a matter of urgency and as a default position by all of them. In the circumstances, a strong case could be made for this reduction of pressures to involve not only greenhouse gas emission reductions but also alleviation of other anthropogenic stressors impacting on ecosystems and making them more vulnerable to deterioration and fundamental changes in structure and functions due to disturbance from global warming.

Third, what types of measures should States employ to progress global efforts to reduce ecological stresses (Section 2.4)? I draw from proposals for a system of ecological governance in other work to suggest that parties' climate actions should be informed by principles such as the substitution of means for meeting policy objectives with lower stress alternatives (a topline approach) and the sunsetting of activities presenting too great a threat of further ecological destabilization for continued reliance on them (the bottom-line approach needed to ensure that substitution promotes an overall decline in ecological pressures). ${ }^{16}$ Strategic planning would also play an important role in supporting a socio-economic transition from the current position to more sustainable ways of living.

Fourth, in what circumstances should departure from the default positions of ecological stress reduction and resilience bolstering be permitted (Section 2.5)? The discussion appreciates that such provision must be made in view of the radical departure from the status quo which addressing the ecological consequences of climate change would require with resulting near-term threats for human well-being. Legal provision allowing departure from a default position of prioritizing stress reduction is therefore recognized as a necessary feature of ecological law whilst noting that the extent to which parties are serious about commitments for ecosystem protection can be judged by how broadly possible justifications for derogation are drawn, and the legal rigour with which requests to take advantage of them are to be policed.

Seven key characteristics which the review in Section 2 indicates an ecologically oriented climate change treaty would possess are set out in Section 3 of the article. Space does not allow for use of the characteristics to analyse the legal framework created by the actual climate change treaties in this article, but some thoughts are presented in Section 4 on how their application could assist with strengthening its ability to promote ecologically positive global change in humanity's relationship with its natural environment.

\section{FORMULATING AN ECOLOGICALLY ORIENTED CLIMATE CHANGE TREATY}

States formulating a treaty whose objectives require preservation of existing ecosystem structures and functions as an outcome of climate action would need to reflect on how global warming threatens ecosystem functionality. Based on this reflection, they would need to determine what commitments they should take on to support ecosystem functionality in the face of climate change. This section examines the key questions which States would need to answer, and matters which States should consider when answering each question. The section is set out in this way to aid readers with following the reasoning that I suggest States would need to employ when deciding on how to combat the ecological effects of climate change.

16 O Woolley, Ecological Governance: Reappraising Law's Role in Protecting Ecosystem Functionality (Cambridge University Press 2014). 


\subsection{How may climate change affect ecosystems?}

Greenhouse gas growth affects ecosystems by modifying conditions with which they interact. ${ }^{17}$ The heat-retaining potential of such gases alters the Earth's climate system. ${ }^{18}$ Planetary-level change can give rise to altered temperature, patterns of rainfall and seasons amongst other phenomena, with the consequences playing out differently in different locations due to regional climatic variation. ${ }^{19}$ This leads to physical change in affected areas (e.g. reduced ice coverage, vegetation loss), the cumulative effect of which may drive further change in the planetary climate system and therefore in the Earth's ecosystems. ${ }^{20}$

Disturbance of ecosystems by climate change impacts them in three main respects. First, it affects their living and non-living components. Change in behaviour of living components and of system composition can alter the functioning and through this the outputs of the relevant ecosystem. Impacts of this kind and related systemic change are already being seen through phenomena such as the shift of species northwards and changes in the timing of biological events. ${ }^{21}$ Biodiversity is impacted negatively as a result, with the diversity between and within species being reduced by species relocating or dying out due to habitat loss or an inability to cope with new conditions. ${ }^{22}$ Second, systemic change may erode resilience, a property possessed by ecosystems which enables them to maintain their existing structures and functions whilst adapting to disruption. ${ }^{23}$ Decline in biodiversity leaves ecosystems less resilient to disturbance. ${ }^{24}$ This is due in part to the loss of redundancy, a term meaning the presence of species in ecosystems able to take on roles previously performed by species that are no longer able to perform them. ${ }^{25}$ Third, climate change challenges ecosystem functionality as an externality. It can overwhelm their resilience to external disturbance on its own or in combination with other stressors, and may cause shifts in the structures and functions of affected systems. ${ }^{26}$ Altered systems resulting from such shifts are often less complex than their predecessors and therefore less able to support a high diversity of species or to yield services valued by humans. ${ }^{27}$

\footnotetext{
17 RK Pachauri and LA Meyer (eds), Climate Change 2014: Synthesis Report (Intergovernmental Panel on Climate Change 2014) (IPCC 2014) 5-6, 10-13.

18 ibid 5-6; National Research Council, Committee on Ecological Impacts of Climate Change, Ecological Impacts of Climate Change (The National Academies Press 2008) 3-9.

${ }^{19}$ IPCC 2014 (n 17) 6-10, 13-17.

20 ibid.

21 ibid 6-7; V Masson-Delmotte et al (eds), Global Warming of $1.5^{\circ} \mathrm{C}$ : Summary for Policymakers (Intergovernmental Panel on Climate Change 2018) 9-16; National Research Council (n 18) 17-21; NB Grimm et al, 'The Impacts of Climate Change on Ecosystem Structure and Function' (2013) 11 Frontiers in Ecology and the Environment 474.

${ }^{22} \mathrm{C}$ Barnard et al, 'Impacts of Climate Change on the future of Biodiversity' (2012) 15 Ecology Letters 365.

${ }^{23}$ SA Levin, 'Ecosystems and the Biosphere as Complex Adaptive Systems' (1998) 1 Ecosystems 431, 433; B Walker and D Salt, Resilience Thinking: Sustaining Ecosystems and People in a Changing World (Island Press 2006) 34-36; Woolley (n 16) 25-37.

${ }^{24}$ Barnard et al (n 22); J Montoya and D Raffaelli, 'Climate Change, Biotic Interactions and Ecosystem Services' (2010) 365 Philosophical Transactions of the Royal Society B 2013.

${ }^{25}$ C Folke et al, 'Regime Shifts, Resilience and Biodiversity in Ecosystem Management' (2004) 35 Annual Review of Ecology, Evolution and Systematics 557, 570-571; Walker and Salt (n 23) 71

${ }^{26}$ Folke et al (n 25); R Biggs, GD Peterson and JC Rocha, 'The Regime Shifts Database: A Framework for Analyzing Regime Shifts in Social-ecological Systems' (2018) (23) Ecology and Society 9.

${ }^{27}$ C Folke, 'Resilience: The Emergence of a Perspective for Social-Ecological Systems Analyses' (2006) 16 Global Environmental Change 253, 257; CS Holling, 'Understanding the Complexity of Economic, Ecological and Social Systems' (2001) 4 Ecosystems 390.
} 
Climatic conditions alter as a natural consequence of dynamism in the Earth's climate system. ${ }^{28}$ Ecosystem outputs may diminish due to impacts on components and relationships between them, but they are able to adapt to disruption whilst retaining existing structures and functions if the change experienced is of a magnitude and at a rate which does not overwhelm their resilience. Gradual variation in externalities has typically been the case during the comparatively benign geological era for human living of the last 10,000 years known as the Holocene ${ }^{29}$ However, the extent and rate of change associated with climate change currently being experienced are unprecedented, marking this variation of planetary conditions out as particularly challenging for ecosystem adaptation to altered conditions. Levels of greenhouse gases have increased exponentially since 1945 and are now thought to be higher than an an point in the last 800,000 years. ${ }^{30}$ The rate of increase in global average temperatures has been similarly dramatic during this 70 -year period. ${ }^{31}$

Concern with the total level of atmospheric greenhouse gases and related alteration of the Earth's climate system can lead to a focus both on change at the planetary level and on targets (e.g. maximum tolerable amounts of greenhouse gas emissions) that are remote from the realities of human dependence on a functioning environment. However, such a focus would be to forget that the ecological consequences of climate change derive ultimately from interaction between local ecosystems and global phenomena. Every ecosystem will react differently to disturbance due to greenhouse gas growth depending on its sensitivity to changing circumstances, existing levels of stress that it is carrying, and its individual capacity for withstanding further disturbance. ${ }^{32}$

Two key conclusions flow from this fact. First, the ecological consequences of climate change depend on the condition of affected ecosystems. A system whose resilience is already much eroded may see further deterioration in its productivity or undergo a regime shift at a lower level of change in climatic conditions than one which is more robust. ${ }^{33}$ Instruments concerned with preserving ecosystem functionality in the face of global warming should therefore require parties to mitigate climate change by reference to its anticipated effects on ecosystems. The slogan 'think global, act local' encapsulates the need for altered human behaviour everywhere as one building block of an effective response to global warming, but its mirror image, 'act global, think local', would be more apposite with regard to tackling the ecological concerns which it raises.

Second, supporting ecosystem functionality by alleviating factors which undermine and threaten to overwhelm their resilience and by restoring this property can prevent harmful climate change by reducing risks of negative ecological impacts. The role of a general commitment to alleviate pressures on and bolster ecosystem resilience is therefore something that parties negotiating an instrument which seeks to preserve ecosystem functionality in the face of climate change should explore. Such an approach may seem misplaced in a climate change regime because of its focus on cumulative pressures and not only those derived from greenhouse gas emissions. However, it would better capture the fact that the ecological consequences of climate change derive from the interaction of externalities such as climate with cumulative natural and anthropogenic stressors, and, in view of this, that ecosystem preservation and restoration contribute to preventing harm.

\footnotetext{
${ }^{28}$ W Steffen et al, Global Change and the Earth System: A Planet Under Pressure (Springer 2004) 71-72; R Boardman, Governance of Earth Systems Science and its Uses (Palgrave Macmillan 2010) 39-43.

${ }^{29}$ J Zalasiewicz and M Williams, 'Climate Change through Earth's History' in TM Letcher (ed), Climate Change: Observed Impacts on Planet Earth (2nd edn, Elsevier 2015) 127.

${ }^{30}$ IPCC 2014 (n 17) 4-5.

${ }^{31}$ ibid; National Research Council (n 18) 3-6.

${ }^{32}$ National Research Council (n 18) 16; Folke et al (n 25) 575; M Scheffer et al, 'Catastrophic Shifts in Ecosystems' (2001) 413 Nature 591, 595-596; IPCC 2014 (n 17) 13.

${ }^{33}$ Woolley (n 16) 21-23; Folke et al (n 25) 575; IPCC 2014 (n 17) 13.
} 
When viewed through an ecological framing, it is strongly arguable that climate action should embrace efforts to support resilience and to revive this where possible as a key means of enabling ecosystems to maintain their structures and functions whilst adapting to climate change. ${ }^{34}$ Conversely, to frame climate change purely as a problem due to greenhouse gas emissions and to create legal structures for mitigating its effects which do not take into account fully the conditions on which it impacts would be likely to prevent an appropriate legal response to its ecological impacts from emerging and therefore of achieving goals of the climate change regime itself, such as maintaining food security, enabling sustainable development, increasing adaptive capacity, and perhaps even reaching net zero greenhouse gas emissions to the extent that States' actions could be inadequate for preventing deterioration in ecosystem services.

\subsection{Predicting ecological effects}

It is clear from the preceding discussion that climate change has the potential to affect ecosystems. However, is knowledge obtainable of how global warming may affect them in practice to support decision making on when action should be taken to address it from an ecological perspective, on what must be done and how quickly? As part of such an analysis, is it possible to tell whether efforts to support ecosystem resilience by reducing cumulative pressures on them and restoring this property may be required? Alternatively, would reducing pressures due to greenhouse gas growth alone be sufficient to combat ecological threats?

Unfortunately, decision making on when, how and how quickly to regulate ecosystemdisrupting activities as causes of potentially problematic change is hampered by significant difficulty with determining how ecosystems may react to disturbance. This is due to several epistemological challenges, including: poor understanding of how cumulative stressors combine to undermine ecosystem functionality and resilience; ignorance of system tipping points beyond which fundamental change in structure and functions becomes inevitable, and of how far an ecosystem lies from them; and difficulties with correlating greenhouse gas growth, global average temperature growth and climatic alteration in different regions. ${ }^{35}$ As a result, it is not possible to predict with accuracy how a particular ecosystem will react to disturbance from growth in greenhouse gas emissions or from other sources.

The precautionary principle could assist the international community with answering the question of whether this is a situation in which it should act notwithstanding scientific uncertainty. There are many variants of the principle, but some common features can be identified including direction that a lack of scientific certainty does not justify inaction and the qualification that this guidance applies only where two preconditions are met. ${ }^{36}$ First, commentators on the principle identify a widely held view that a more than hypothetical threat of harm must be present to justify precautionary action. ${ }^{37}$ Second, a condition is found in most

\footnotetext{
${ }^{34}$ GM Woodwell, 'On Purpose in Science, Conservation and Government: The Functional Integrity of the Earth is at Issue Not Biodiversity' (2002) 31 Ambio 432; M MacDonald, 'Climate Change and Security: Towards Ecological Security' (2018) 10 International Theory 153.

${ }^{35}$ Woolley (n 16) 18-37, 54-56; R Biggs et al, 'Principle 3 - Manage Slow Variables and Feedbacks' in R Biggs, M Schlüter and ML Schoon (eds), Principles for Building Resilience: Sustaining Ecosystem Services in SocialEcological Systems (Cambridge University Press 2015) 141.

${ }^{36} \mathrm{~N}$ de Sadeleer, Environmental Principles: From Political Slogans to Legal Rules (Oxford University Press 2002) 156-158; R von Schomberg, 'The Precautionary Principle and its Normative Challenges' in E Fisher, J Jones and R von Schomberg (eds), Implementing the Precautionary Principle: Perspectives and Prospects (Edward Elgar 2006) 19, 40; A Trouwborst, 'The Precautionary Principle in General International Law: Combating the Babylonian Confusion' (2007) 16 Review of European, Comparative and International Environmental Law 185, 188-189.

${ }^{37}$ de Sadeleer (n 36) 157-162; von Schomberg (n 36) 19 and 40; Trouwborst (n 36) 188.
} 
variants of the precautionary principle that threats posed should be serious, significant and/or irreversible to justify a precautionary response. ${ }^{38}$

Both questions should be answered in the affirmative if States stand by the statements set out in the introduction to this article, some of which recognize that climate change presents a tangible and significant threat of ecological harm. The principle's relevance in this context is recognized in the UNFCCC which advises parties that they 'should take precautionary measures to anticipate, prevent or minimize the causes of climate change and mitigate its adverse effects'. ${ }^{39}$ In any event, it would be difficult to argue that these conditions are not met in light of knowledge of how much more gradual periods of change than those currently being experienced have affected ecosystems in the past. ${ }^{40}$

\subsection{Addressing ecological threats on a precautionary basis}

States would also be affected by the epistemological challenges considered above when deciding not only on whether they should act to address the threat posed by climate change for ecosystem functionality, but also on how intrusive in the functioning of socio-economic systems action should be and how quickly it should be taken. Inabilities to predict the ecological impacts of activities reliably and to identify points at which negative change may occur or how far removed ecosystems are from them would prevent precise identification of measures required to avoid feared outcomes and of the rate at which they should be taken. They would need to agree on some proxy metric for directing parties' actions and for assessing their performance. Without this, there would be every possibility for progress by proactive parties being cancelled out by those moving at slower rates on emission and stress reduction without the pressure of normative yardsticks to highlight their tardiness.

Whatever States conclude on this, they would be able if they so choose to draw from academic scholarship on decision making under scientific uncertainty when deciding on how they should act to address the threat posed by climate change for ecosystem functionality. ${ }^{41} \mathrm{Of}$ particular relevance in this case is the argument made by some commentators on the precautionary principle that a more than hypothetical threat of catastrophic environmental harm would justify a substantial and rapid response to forestall it even if the likelihood of its happening were thought to be low. ${ }^{42}$ There are strong grounds for arguing that significant further deterioration in ecosystem functionality of the type which can be expected to occur through exacerbation of the already reported global ecological degradation by climate change falls into this potentially 'catastrophic' category and therefore that the international community should respond to this situation with a due sense of urgency. The centrality of ecosystem

\footnotetext{
38 de Sadeleer (n 36) 161-167; A Trouwborst, Precautionary Rights and Duties of States (Brill 2006) 37-69; Trouwborst (n 36) 188-189.

${ }^{39}$ UNFCCC (n 1) art 3(3).

40 The National Academy of Sciences, Ecological Impacts of Climate Change (The National Academies Press 2009) 25-26; JL Blois et al, 'Climate Change and the Past, Present and Future of Biotic Interactions' (2013) 341 Science 499; M Dickinson, IC Prentice and G Mace, 'Climate Change and Challenges for conservation (Grantham Institute, Imperial College London 2015) <https:/www.imperial.ac.uk/media/imperial-college/granthaminstitute/public/publications/briefing-papers/Climate-change-and-challenges-for-conservation-Briefing-PaperNo-13.pdf $>$.

41 JB Wiener, 'Precaution' in D Bodansky, J Brunnée, and E Hey (eds), The Oxford Handbook of International Environmental Law (Oxford University Press 2007) 597, 598, 607-610; C Vlek, 'Judicious Management of Uncertain Risks' (2010) 13 Journal of Risk Research 517 and 545; Woolley (n 16) 59-67.

42 J van der Sluijs and W Turkenburg, 'Climate Change and the Precautionary Principle' in Fisher et al (n 36) 245; Wiener (n 41) 608; A Klinke and O Renn, 'Adaptive and Integrative Governance on Risk and Uncertainty' (2012) 15 Journal of Risk Research 273, 284-286; JB Wiener, 'Precaution and Climate Change' in CP Carlane, KR Gray and R Tarasofsky (eds) The Oxford Handbook of International Climate Change Law (Oxford University Press 2016) 163, 169-170.
} 
'services' to the quality and even viability of human living means that deterioration in ecosystem functionality can have serious consequences. It may threaten the well-being not only of those immediately dependent on them, but also of people distant from them in view of the potential for ecosystem change in one area to affect conditions in others (due to ecosystem influences on planetary systems). Deterioration of one ecosystem may lead to a vicious spiral of ecosystem decline as demand for support migrates to still 'healthy' systems when others deteriorate and fail. It may impact on a global economic system in which many States have become dependent on imports of commodities from remote jurisdictions whilst the economies of others depend on their export. In addition, it may deny opportunities for the poorest States to pursue sustainable development and for their populations to attain internationally recognised needs and rights for human life. ${ }^{43}$

Grounds for fearing that risks of catastrophic decline in ecological support for life, even if they cannot be quantified, may be substantial and growing add to evidence that urgent action is required. First, the rate of climate change is unprecedented, confronting ecosystems with a speed of change which evidence from geoscience suggests they will not have experienced in millennia. ${ }^{44}$ Second, climate change occurs at a time when ecosystem functionality and resilience is known to be undergoing a period of rapid and accelerating global deterioration. ${ }^{45}$ Third, it also coincides with a deterioration in biodiversity, believed to be a principle source of ecosystem resilience, ${ }^{46}$ at a human-driven rate likened to previous extinction events caused by non-anthropogenic externalities such as meteor strikes and volcanic eruptions. ${ }^{47}$ Rockström and colleagues argue that this deterioration has reached a point where, as with climate change, it is altering conditions not only of individual ecosystems, but also at the planetary level. ${ }^{48}$

Two further considerations amplify concerns with this situation. First, the reaction of ecosystems to disturbance is non-linear. Accordingly, they may not show signs of deterioration corresponding to the impact human pressures are having on them or of the imminence of a shift before undergoing radical change. ${ }^{49}$ Second, systemic change is not certain to be reversed by a simple reduction in factors responsible for a regime shift (a phenomenon known as hysteresis) ${ }^{50}$ The potent combination of inability to detect the imminence of change and the possibility that it may be irreversible should further focus attention on grounds for believing that this is a period of heightened risk for ecosystem functionality in the present rather than waiting for further detailing of pathways by which threats may crystallize.

In summary, accurate predictions of harm and timing may not be available to support decision making on how climate change should be tackled from an ecological perspective. However, it is strongly arguable based on the reasoning above that: (i) drivers of climate change should be addressed with urgency to alleviate the threat it poses to already threatened ecosystems; (ii) the combination of a threat of catastrophic harm, evidence suggesting that this is a period of particular sensitivity for ecosystem health, and practical difficulties with a wait-

\footnotetext{
${ }^{43}$ J Bouma and P van Beukering, 'Ecosystem Services: from Concept to Practice' in J Bouma and P van Beukering (eds), Ecosystem Services: from Concept to Practice (Cambridge University Press 2015) 3.

${ }^{44}$ IPCC 2014 (n 17) 4-5.

${ }^{45}$ Millennium Ecosystem Assessment, Ecosystems and Human Well-being: Synthesis (Island Press 2005); World Wildlife Fund, Living Planet Report 2018: Aiming Higher (World Wildlife Fund 2018).

46 TH Oliver et al, 'Biodiversity and Resilience of Ecosystem Functions' (2015) 30 Trends in Ecology and Evolution 673.

${ }^{47}$ J Rockström et al, 'Planetary Boundaries: Exploring the Safe Operating Space for Humanity' (2009) 14 Ecology and Society 32.

48 ibid; J Rockström et al, 'A Safe Operating Space for Humanity’ (2009) 461 Nature 472.

${ }^{49}$ Scheffer et al (n 32) 595-596; R Biggs, SR Carpenter, and WA Brock, 'Turning Back from the Brink: Detecting an Impending Regime Shift in Time to Avert It' (2009) 106 Proceedings of the National Academy of Sciences of the United States of America 826; Biggs et al (n 35) 110-120.

${ }^{50}$ Biggs et al (n 35) 116-118.
} 
and-see approach would justify simultaneous action to reduce pressures on ecosystems from other sources and to restore their resilience with equal urgency; and (iii) the line of reasoning set out above calls for a default position that States should reduce pressures on ecosystem functionality attributable to them with a view to ensuring their progressive reduction from current levels.

\subsection{Action required to advance ecological objectives}

The analysis above points to the need for laws which facilitate movement away from the current situation on a precautionary basis. I leave detailed examination of legal tools for enabling this to future research, but note the particular importance of characteristics that law capable of engendering a rapid retreat from a position of potentially catastrophic harm in circumstances of profound uncertainty should possess. ${ }^{51}$ First, a principle for State decision making of preferring activities expected to place least pressure on ecosystems amongst available options should be adopted. ${ }^{52}$ To give this principle effect, it would need support from mechanisms requiring analysis of how pressures on the natural world arise as a basis for exploring movement away from the situation. ${ }^{53}$ Second, a firm bottom line, corresponding to a principle that activities posing too great a threat in the present circumstances should be eradicated (e.g. those leading to any further greenhouse gas emissions) would be required to make laws for promoting less ecologically stressful activities effective for pressure reduction. ${ }^{54}$ As with the principle of preferring the least ecologically stressful options for meeting human needs, a principle of eschewing options presenting too great a level of ecological threat in the present situation would require support from mechanisms for the development and implementation of strategies for their withdrawal over the quickest possible timescale. ${ }^{55}$

Pursuing policies for the progressive reduction of anthropogenic pressures on ecosystem functions, withdrawing and prohibiting activities judged to present too great an ecological threat for future recourse to them, and maintaining and restoring the resilience and functioning of ecosystems are necessary in a context of potentially catastrophic threat to the ability of ecosystems to support life coupled with unknowability of the degree of further interference that may realize that threat for ecosystems individually or at a planetary scale. However, this essential narrowing of parameters for tolerable human activities would inevitably present greater difficulties than already exist for reaching a climate settlement that all of the world's States and their peoples consider to be equitable. ${ }^{56}$ Responses to this unjust situation would be needed when formulating a regime for addressing global warming which prioritizes ecosystem preservation as an outcome if it is to be accepted as fair by States whose room to develop on the same terms as developed States has been restricted. ${ }^{57}$ This would involve using levers for enhancing perceived equitability such as climate finance, technology

\footnotetext{
${ }^{51}$ Woolley (n 16) 67-93.

52 ibid 71-76; R Giljam, 'Better BAT to Bolster Ecosystem Resilience: Operationalizing Ecological Governance through the Concept of Best Available Techniques' (2017) 26 Review of European, Comparative and International Environmental Law 5; Swedish Chemicals Agency, 'The Substitution Principle' (2007) $<$ https://www.kemi.se/en/global/rapporter/2007/rapport-8-07-the-substitution-principle.pdf $>$.

${ }^{53}$ Woolley (n 16) 77-93; P Vergragt and J Quist, 'Backcasting for Sustainability: Introduction to the Special Issue' (2011) 78 Technological Forecasting and Social Change 747, 747-9; J Robinson, 'Futures under Glass: A Recipe for People who Hate to Predict' (1990) 22 Futures 820, 828-830.

${ }^{54}$ Woolley (n 16) 76-77; Giljam (n 52); ES Kim, 'Chemical Sunset: Technological Inflexibility and Designing an Intelligent Precautionary “Polluter Pays” Principle’ (2008) 33 Science, Technology and Human Values 459.

${ }^{55}$ Woolley (n 16) 77-93; Klinke and Renn (n 42) 282-284.

${ }^{56}$ P Cullet, 'Common but Differentiated Responsibilities' in M Fitzmaurice, D Ong and P Merkouris (eds), Research Handbook on International Environmental Law (Edward Elgar 2010) 161; X Ngwadla, 'An Operational Framework for Equity in the 2015 Agreement' (2014) 14 Climate Policy 8.

${ }^{57}$ D Shelton, 'Equity' in D Bodansky et al (n 41) 640.
} 
transfer and capacity building as well as linking support from developed and wealthier developing States with global initiatives for addressing poverty and enabling sustainable development. ${ }^{58}$ Consideration should also be given to ways in which these levers can be used to promote ecosystem preservation and restoration by situating them within a more sustainable developmental framework which rewards actions contributing to the restoration of ecosystem resilience rather than its erosion.

\subsection{Derogation from core obligations}

'Movement away' from practices that have become globally entrenched, such as greenhouse gas-emitting resource consumption and States living beyond their ecological means, will inevitably create nearer-term problems with the functioning of socio-economic systems including, for example, the availability and affordability of fuel and food. ${ }^{59}$ Any climate change agreement should recognize these realities and that the rate at which States are able to tackle its effects may be constrained by them by allowing non-compliance by parties with core obligations for addressing sources of environmental harm. However, it should also limit the resulting scope for action to become delayed by endless wrangling over what is feasible or appropriate to expect of a State by defining justifications for delay with clarity and establishing mechanisms for reviewing and validating them. States would need to make difficult choices over trade-offs between reducing pressures on ecosystems and other objectives, and it is not possible to draw a clear line between them objectively. Even so, I suggest that the rigour with which grounds for departing from core obligations are defined and policed can be regarded as an indicator of the seriousness of commitment made by parties to a treaty to achieve its goals.

\section{ECOLOGICAL CLIMATE LAW: KEY CHARACTERISTICS}

The review in Section 2 of questions that States would need to consider when formulating a treaty concerned with preserving ecosystem functionality in the face of global warming reveals seven key characteristics which such a treaty and, by extension, national programmes for given effect to its goals, should possess. The reason for identifying the characteristics, as considered in Section 1 of this article, is to enable critical analysis both of whether the actual treaties establish an appropriate framework for addressing climate change from an ecological perspective, and of how the capacity of the regime which they establish for preventing ecosystem deterioration and collapse could be enhanced. The characteristics are as follows:

1. Requirements for parties to mitigate climate change by reference to its anticipated effects on ecosystems (Section 2.1).

2. Requirements for parties to respond to the catastrophic threats posed by global warming with a due sense of urgency in mitigation (Section 2.3). As I suggest in this section, the urgency with which mitigation is to be conducted serves as an indicator of parties' actual degree of commitment to achieving goals involving reducing risks of ecosystem deterioration and regime shifts by combatting the ecological effects of climate change.

3. Requirements for parties to alleviate pressures on and to bolster ecosystem resilience simultaneously with action to reduce greenhouse gases (Sections 2.1 and 2.3)

4. Requirements for parties to reduce pressures on ecosystems from all sources and to restore their resilience with equal urgency to climate change mitigation (Sections 2.1 and 2.3). As with point 2 above, I suggest that the urgency with which action to reduce

58 United Nations Department of Economic and Social Affairs, 'Sustainable Development Goals', $<$ https://sustainabledevelopment.un.org/?menu=1300 $>$.

${ }^{59}$ IPCC 2014 (n 17) 75-91. 
factors eroding ecosystem resilience and to bolster this property is taken serves as a key indicator of parties' actual degree of commitment to achieving goals involving reducing risks of deterioration and regime shifts in ecosystems confronted by climate change.

5. Principles and mechanisms designed to assist parties individually and in collaboration with developing and implementing effective strategies for rapid movement of socioeconomic systems away from the current unsustainable position and toward more sustainable ways of being (Section 2.4). They may include principles of substituting human activities with less ecologically stressful alternatives and of 'sunsetting' activities presenting too high a degree of threat to ecosystem functionality for continued reliance on them. ${ }^{60}$ The inclusion of legal requirements for long-term planning and arrangements to support plan formation such as preliminary assessment of how sources of pressure attributable to a State arise and of how opportunities for replacing them with less stressful alternatives (including the preferred outcome of non-consumption) are also indicative of an ecological approach. ${ }^{61}$

6. Legal provision for strands of climate action which seek to enhance the perceived equitability of a settlement such as climate finance, technology transfer, capacity building, and financial incentives for mitigation/adaptation projects in ways which seek to ally objectives such as alleviating poverty and improving living conditions with those for strengthening ecosystem resilience (Section 2.4).

7. Careful definition of grounds on which derogation from the default positions of points 2, 4 and 5 above can be justified, and legal rigour in the review of derogation requests with the breadth of grounds justifying derogation and the rigour with which recourse to them is policed serving as key indicators of the seriousness of parties' commitments to addressing the ecological effects of climate change (Section 2.5).

The appearance of some of these characteristics in a treaty but not others may show that parties are aware of the need for a specific response to risks of ecological harm posed by climate change, but that they have not understood or are unwilling to accept the ramifications of those risks in full. For example, Sections 1 and 4 of this article refer to provisions of the Paris Agreement which show awareness of the threat posed by climate change for ecosystems by calling on parties to aid adaptation by protecting ecosystems and strengthening their resilience. ${ }^{62}$ However, the provisions are silent on how parties should go about this and how quickly. They also lack support from mechanisms of the type discussed in Section 2.4 for assisting in the socio-economic transition. The absence of detail suggests that States did not feel able, when drafting the Agreement, to face up to conclusions flowing from an ecological analysis of climate change about the need for rapid and radical responses to the current unsustainability of human living. ${ }^{63}$

\section{ECOLOGIZING INTERNATIONAL CLIMATE LAW}

Space does not allow for a full review of the climate change treaties using these characteristics. However, it is possible without undertaking this to suggest two ways in which the conclusions reached in this article could be used to shape the climate change regime's evolution with the aim of promoting its effectiveness for ecosystem preservation. First, States recognize in the Paris Agreement's adaptation article that the protection of ecosystems 'is a key component of and makes a contribution to the long-term global response to climate change', and include

\footnotetext{
${ }^{60}$ Woolley (n 16) 71-77.

${ }^{61}$ ibid 77-93.

${ }^{62}$ Paris Agreement (n 2) arts 2(1)(b), 7(2) and 7(9)(d).

${ }^{63}$ See Section 4.
} 
'[b]uilding the resilience of socioeconomic and ecological systems, including through economic diversification and sustainable management of natural resources' in an indicative list of steps which parties may wish to consider when performing an obligation to engage in adaptive planning processes and the implementation of actions. ${ }^{64}$ They also adopt goals of strengthening the global response to the threat of climate change by 'increasing the ability to adapt to the adverse impacts of climate change and foster climate resilience and low greenhouse gas emissions development' and 'of enhancing adaptive capacity, strengthening resilience and reducing vulnerability to climate change, with a view to contributing to sustainable development and ensuring an adequate response in the context of the temperature goal referred to in Article 2' ${ }^{65}$ Neither goal mentions ecosystem preservation expressly, but it is clear from the review at Section 2.1 that arresting drivers of deterioration in ecosystem resilience and enhancing this property are central to promoting human survival in a climatically altered world.

The statements and goals are rather vague about what is to be achieved, and require much further detailing if they are to be elevated beyond the aspirational. ${ }^{66}$ Even so, their adoption creates opportunities for exploration by parties of the central role of ecosystem preservation and restoration in achieving the increased resilience and reduced vulnerability they seek. Opportunities may also arise to establish principles for reducing pressures on ecosystems and bolstering their resilience as norms of climate action when developing metrics for assessing progress by States individually and together with advancing the adaptation goals including under the five-yearly global stocktake that will assess the cumulative progress of parties towards achieving the Agreement's long-term goals. ${ }^{67}$ This method of review has particular potential to be influential as parties have an obligation under the Paris Agreement to 'be informed by the outcomes' of global stocktakes when preparing their successive nationally determined contributions. ${ }^{68}$

Matters to explore when detailing the adaptation provisions and developing related metrics include conflict between the Paris Agreement's positions on mitigation and adaptation. The provisions and goals mentioned above envisage expressly or by implication in their calls for resilience to be enhanced and vulnerability reduced that parties will act in ways conducive to preserving ecosystem functionality. However, whatever efforts are made to reduce pressures on and enhance resilience under the adaptation branch of climate action may be undermined due to the lack of a clear requirement under any of the climate change treaties for parties to mitigate climate change by reference to ecological considerations. ${ }^{69}$ This is just one example of several creative tensions between different strands of action under the climate change regime whose resolution would point to the conduct of mitigation and adaptation by reference to common ecological metrics and at a common rate with greenhouse gas emission reduction forming part of a wider programme of measures to strengthen ecosystem resilience. Such tensions also arise between the UNFCCC's obligation and the Paris Agreement's expectation for parties to preserve and enhance ecosystems performing carbon regulation services as

\footnotetext{
${ }^{64}$ Paris Agreement (n 2) arts 7(2) and 7(9)(d).

65 ibid arts 2(1)(b) and 7(1).

${ }^{66}$ AK Magnan and T Ribera, 'Global Adaptation after Paris' (2016) 352 Science 1280.

${ }^{67}$ Paris Agreement (n 2) art 14.

${ }^{68}$ ibid art 4(9).

${ }^{69}$ The UNFCCC's (n 1) ultimate objective (art 2) and some of its principles for State climate action (arts 3(1) and 3(3)) could be interpreted as directing parties that their decision making on climate actions should take into account the ecological effects of climate change with a view to preserving ecosystem functionality. Unfortunately, the relevant provisions are not clear enough about either desired outcomes or actions required to achieve them to provide a basis for assessing the adequacy of steps taken by States individually and collectively under the climate change regime from an ecological perspective. See Bodanksy et al (n 1), 123-129. See also the arguments in Sections 2.1 and 2.3 that mitigation would be informed by ecological considerations and pursued with due urgency under a climate change treaty making appropriate provision for ecosystem preservation.
} 
reservoirs and sinks of climate change and the lack of a requirement for parties' reduction of greenhouse gas emissions to be conducted in ways and at a rate which maximizes chances that natural storehouses of carbon will persist despite alteration in planetary conditions. ${ }^{71}$

Second, the Paris Agreement includes obligations and expectations and proposes procedures for the reporting and review of steps taken by parties under the Agreement in its transparency framework. ${ }^{72}$ The framework plays a central role in pressurizing parties to improve their ambition under an Agreement in which parties self-determine what contributions they will make to international climate action. ${ }^{73}$ As noted above with regard to adaptation, the detailing of requirements for reporting and of the basis on which the review of reports and submissions will be conducted offers general scope for introducing the presence of all of the characteristics of an ecologically oriented climate change agreement identified in this article as normative expectations for judging the adequacy of parties' nationally determined contributions. In this regard, rules adopted at the Katowice climate conference in 2018 on voluntary reporting of national adaptation actions and on reviewing the collective performance of States with achieving the goals set out above under the global stocktake create potential needs for means of assessing the adequacy of parties' climate actions at national and international levels including with regard to reducing risks of climate-driven ecosystem deterioration. ${ }^{74}$ For example, the technical dialogue component of the global stocktake will 'assess collective progress towards' achieving the Paris Agreement's purpose and long-term goals including those relating to adaptation. ${ }^{75}$ Parties are also expected when reporting on adaptation actions to record actions relating to ecosystem preservation such as "nature-based solutions to climate change adaptation' and the development and use of indicators for assessing matters such as the sufficiency of action taken to increase resilience and thereby avert impacts. ${ }^{76}$ Developments such as these offer encouraging signs that the Agreement's adoption has opened up a space for promoting responses to climate change in line with responding to the threat it presents to the Earth's ecological ability to support life.

\section{CONCLUSION}

The analysis presented in Section 2 of this article aims to provide a basis for assessing the appropriateness of the legal framework created by the UNFCCC, the Kyoto Protocol and the Paris Agreement for addressing the ecological consequences of global warming. The characteristics set out in Section 3 can be used both to identify current flaws in the legal framework created by relevant treaties and to highlight ways in which its ability to promote ecosystem preservation could be strengthened. The discussion in Section 4 of provisions concerning adaptation and transparency under the Paris Agreement and of how they are being fleshed out reveals opportunities created by the adoption of this instrument to introduce ecological considerations as a guide for parties' climate actions. It is to be hoped that such

\footnotetext{
${ }^{71} \mathrm{UNFCCC}$ (n 1) art 4(1)(d); Paris Agreement (n 2) art 5(1).

72 Paris Agreement (n 2) art 13.

73 O Woolley, 'Developing Countries under the International Climate Change Regime: How Does the Paris Agreement Change Their Position?' in Z Yihdego, M Desta and M Fikremarkos (eds), Ethiopian Yearbook of International Law (Springer 2016) 179.

${ }^{74}$ See UNFCCC 'Report of the Conference of the Parties Serving as the Meeting of the Parties to the Paris Agreement on the Third Part of Its First Session, Held in Katowice from 2 to 15 December 2018' UN Doc FCCC/PA/CMA/2018/3 (19 March 2019).

${ }^{75}$ UNFCCC 'Decision 19/CMA.1, Matters Relating to Article 14 of the Paris Agreement and Paragraphs 99-101 of Decision 1/CP.21' UN Doc FCCC/PA/CMA/2018/3/Add.2 (19 March 2019) para 6.

${ }^{76}$ UNFCCC 'Decision 18/CMA.1, Modalities, Procedures and Guidelines for the Transparency Framework for Action and Support Referred to in Article 13 of the Paris Agreement' UN Doc FCCC/PA/CMA/2018/3/Add.2 (19 March 2019) Annex, paras 104-117.
} 
opportunities are taken, and that this leads States to appreciate that an ecologically oriented response to global warming along the lines proposed in this article is needed to maximize prospects of sustaining the Earth's ecological capacity to support life despite human-driven planetary change.

Dr Olivia Woolley is a senior lecturer in environmental and energy law of the School of Law at the University of Aberdeen. She examines how law could be used more effectively to support ecosystem functionality in her research, and has had several publications on this topic including Ecological Governance (Cambridge University Press 2014). Olivia also specializes in law relating to a low-carbon energy transition, with particular interests in renewable energy and the generation and transmission of energy from offshore renewable sources. Olivia worked in a London law firm as a solicitor specializing in dispute resolution in the energy and construction sectors for a decade before returning to academia in 2007 to undertake doctoral research in environmental law at University College London. She worked as a postdoctoral researcher at the University of Groningen Centre for Energy Law before moving to Aberdeen in 2013. 